\title{
Tribological Properties of Copper Molybdate Powder Solid Lubricants under High Temperature Conditions
}

\author{
Yoshinori Takeichi $^{1)^{*}}$, Masato Inada $^{1)}$, Kentaro Minami ${ }^{1)}$, Masahiro Kawamura ${ }^{2)}$ and Marian Dzimko ${ }^{3)}$ \\ ${ }^{1)}$ Department of Mechanical Engineering, Toyohashi University of Technology \\ 1-1 Hibarigaoka, Tempaku, Toyohashi, Aichi 441-8580, Japan \\ ${ }^{2)}$ Kawamura Research Laboratory Co. Ltd. \\ 1-5-6 Meguro, Meguro, Tokyo 153-0063, Japan \\ ${ }^{3)}$ Faculty of Mechanical Engineering, University of Žilina \\ Univerzitná 1, 010 26, Žilina, Slovak Republic \\ *Corresponding author: takeichi@tut.jp \\ ( Manuscript received 2 January 2014; accepted 26 August 2014; published 15 April 2015 ) \\ (Presented at Technical Session in the $5^{\text {th }}$ World Tribology Congress TORINO September 2013)
}

\begin{abstract}
In our previous research, it was suggested that a sort of copper molybdate $\mathrm{Cu}_{3} \mathrm{Mo}_{2} \mathrm{O}_{9}$ generated on the friction track of aluminum bronze coated with $\mathrm{MoO}_{3}$ powder reduced friction under high temperature conditions. In order to study the lubricity of copper molybdate as high temperature lubricant, the lubrication properties of two kinds of copper molybdate powders, $\mathrm{CuMoO}_{4}$ and $\mathrm{Cu}_{3} \mathrm{Mo}_{2} \mathrm{O}_{9}$, were studied by comparing with the lubricity of $\mathrm{CuO}$ and $\mathrm{MoO}_{3}$ powders. These powders were supplied to the sliding surface of the stainless steel specimens as solid lubricant and the friction test was conducted at various ambient temperatures ranging from room temperature to $700^{\circ} \mathrm{C} . \mathrm{Cu}_{3} \mathrm{Mo}_{2} \mathrm{O}_{9}$ and $\mathrm{CuMoO}_{4}$ powders were synthesized by heating the mixture of $\mathrm{CuO}$ and $\mathrm{MoO}_{3}$ powders in their own specific heating conditions and identified by XRD. Both of $\mathrm{Cu}_{3} \mathrm{Mo}_{2} \mathrm{O}_{9}$ and $\mathrm{CuMoO}_{4}$ powders showed lower friction coefficient and smaller wear amount of specimen with increasing ambient temperature. On the other hand, $\mathrm{CuO}$ and $\mathrm{MoO}_{3}$ powders showed poor lubricating ability and high wear amount of specimens comparing with two kinds of copper molybdate powders. It was suggested that the enhanced maintaining abilities of copper molybdate on the stainless steel substrate at high temperature and generation of unoxidized copper under high temperature conditions could enhance lubricating abilities.
\end{abstract}

Keywords: high temperature, copper molybdate, solid lubricant, $\mathrm{Cu}_{3} \mathrm{Mo}_{2} \mathrm{O}_{9}, \mathrm{CuMoO}_{4}$, copper oxide, molybdenum trioxide, adhesiveness

\section{Introduction}

Lubrication properties of many kinds of solid materials as high temperature lubricant have been studied. One of effective materials which can be used under high temperature conditions is metal oxide. The lubricity of many kinds of oxides and double oxides at high temperature has been studied and some of them showed excellent lubricity at high temperature [1-3]. Molybdenum trioxide $\left(\mathrm{MoO}_{3}\right)$ showed lubricity (friction coefficient of about 0.2 ) as a solid lubricant in the sliding between the nickel chrome alloys at about $700^{\circ} \mathrm{C}$ [1].

The effects of $\mathrm{MoO}_{3}$ powder as a high temperature lubricant on the friction and wear properties of aluminum bronze were studied [4]. $\mathrm{MoO}_{3}$ powder supplied to the sliding surface reduced friction and wear of materials at the temperature of over $500^{\circ} \mathrm{C}$. As the result of X-ray diffraction analysis of the friction track tested at high temperature, it was revealed that one of copper molybdates, $\mathrm{Cu}_{3} \mathrm{Mo}_{2} \mathrm{O}_{9}$, was generated on the friction track during sliding at high temperature. It was suggested that $\mathrm{MoO}_{3}$ didn't work directly as a high temperature lubricant, but it reduced friction and wear by changing into copper molybdate.

Wahl et al. reported that the ion-beam deposited amorphous $\mathrm{Cu}-\mathrm{Mo}$ coating on alumina substrates changed to crystalline oxide at high temperature and showed low friction coefficient at 530 and $650^{\circ} \mathrm{C}$ [5]. This oxide was not completely identified but they suggested this crystalline oxide could be one of copper molybdates. They concluded that the oxide softened above their ductile-to-brittle temperature and then relative softness of the oxide with respect to the 
substrate reduced friction. Copper molybdates have been well investigated as a catalyst in the field of material research [6-8]. However, as far as we know, the lubricity of copper molybdate has not been fully investigated.

In order to study the lubrication mechanism of copper molybdate under high temperature conditions, the lubricity of two kinds of copper molybdates, $\mathrm{Cu}_{3} \mathrm{Mo}_{2} \mathrm{O}_{9}$ and $\mathrm{CuMoO}_{4}$, under several temperature conditions were compared with the lubricity of $\mathrm{CuO}$ and $\mathrm{MoO}_{3}$. In this experiment, two kinds of copper molybdate powders were synthesized from $\mathrm{CuO}$ and $\mathrm{MoO}_{3}$ powders.

\section{Experiments}

\subsection{Sample Preparation - Copper Molybdate}

Copper molybdate has various kinds of stoichiometric or non-stoichiometric compounds [9-12]. Both of copper molybdates, $\mathrm{Cu}_{3} \mathrm{Mo}_{2} \mathrm{O}_{9}$ and $\mathrm{CuMoO}_{4}$, are stoichiometric compounds of $\mathrm{CuO}$ and $\mathrm{MoO}_{3}$. In

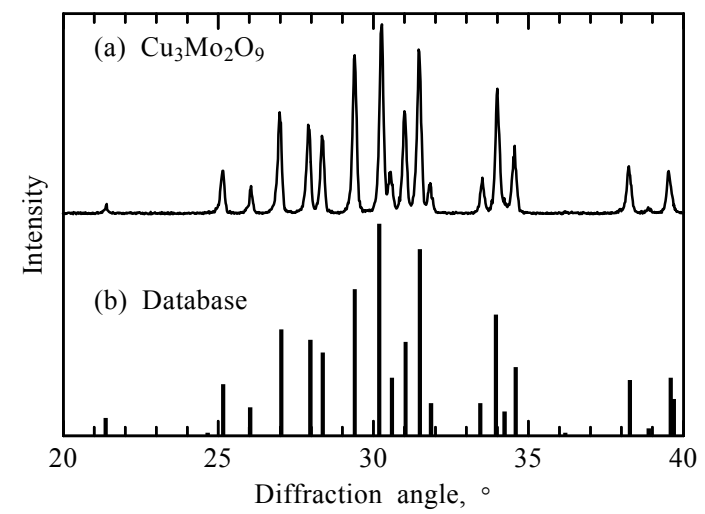

Fig. 1 (a) XRD spectrum obtained from synthesized $\mathrm{Cu}_{3} \mathrm{Mo}_{2} \mathrm{O}_{9}$ powder and (b) diffraction peak patterns referred from the database

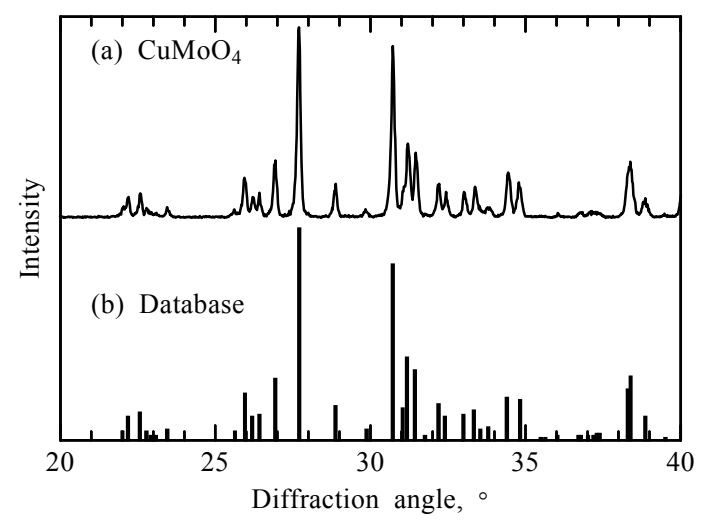

Fig. 2 (a) XRD spectrum obtained from synthesized $\mathrm{CuMoO}_{4}$ powder and (b) diffraction peak patterns referred from the database

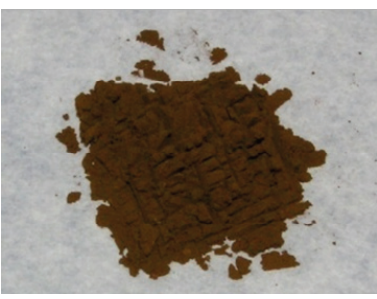

(a)

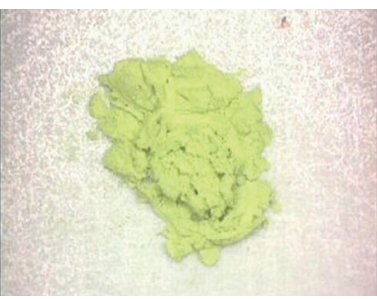

(b)
Fig. 3 (a) $\mathrm{Cu}_{3} \mathrm{Mo}_{2} \mathrm{O}_{9}$ powder and (b) $\mathrm{CuMoO}_{4}$ powder synthesized by heating the mixture of $\mathrm{CuO}$ and $\mathrm{MoO}_{3}$ powders in their own specific heating conditions

this experiment, these copper molybdates were obtained by heating mixed $\mathrm{CuO}$ and $\mathrm{MoO}_{3}$ powders in air. Commercially available $\mathrm{CuO}$ and $\mathrm{MoO}_{3}$ powders were used as base materials and their purities are 99 and $99.5 \%$ respectively. The average particle sizes of $\mathrm{CuO}$ and $\mathrm{MoO}_{3}$ powder were 1.9 and $1.6 \mu \mathrm{m}$ respectively. These powders were mixed and homogeneously dispersed by mixing well in a mortar. The mixing mass ratio of these two powders was calculated based on the stoichiometric ratio of each composite. The heating temperature and heating period for $\mathrm{Cu}_{3} \mathrm{Mo}_{2} \mathrm{O}_{9}$ powder were $700^{\circ} \mathrm{C}$ and 1 hour, and those for $\mathrm{CuMoO}_{4}$ powder were $500^{\circ} \mathrm{C}$ and 12 hours [13] respectively.

The X-ray diffraction spectra were obtained from these heated mixed powders by using cobalt X-ray source, in order to confirm that these synthesized two kinds of materials were $\mathrm{Cu}_{3} \mathrm{Mo}_{2} \mathrm{O}_{9}$ and $\mathrm{CuMoO}_{4}$. Figures 1(a) and 2(a) show the obtained X-ray diffraction spectra and Figs. 1(b) and 2(b) show the diffraction peak patterns referred from the database for $\mathrm{Cu}_{3} \mathrm{Mo}_{2} \mathrm{O}_{9}$ (JCPDS 01-070-1495) and $\mathrm{CuMoO}_{4}$ (JCPDS 01-085-1530) respectively. Here, database peak position was converted with consideration for the difference of the wavelength of X-ray emitted from copper target and that from cobalt target. Both spectra obtained from two kinds of heated mixed powders are in good agreement with each database. As the result of peak pattern matching, these synthesized materials were identified as each copper molybdate, $\mathrm{CuMoO}_{4}$ and $\mathrm{Cu}_{3} \mathrm{Mo}_{2} \mathrm{O}_{9}$.

Two kinds of copper molybdates showed different color as shown in Fig. 3. $\mathrm{Cu}_{3} \mathrm{Mo}_{2} \mathrm{O}_{9}$ is dark brown powder (Fig. 3(a)) and $\mathrm{CuMoO}_{4}$ is bright yellowish powder (Fig. 3(b)). Figure 4 shows microscopic structure of (a) $\mathrm{Cu}_{3} \mathrm{Mo}_{2} \mathrm{O}_{9}$, (b) $\mathrm{CuMoO}_{4}$, (c) $\mathrm{CuO}$ and (d) $\mathrm{MoO}_{3}$ powders obtained by scanning electron microscope. The shape and size of both copper molybdate particles are different from $\mathrm{CuO}$ or $\mathrm{MoO}_{3}$. It seems that copper molybdate particles fused each other and grown to larger particles.

\subsection{Sample Preparation - Specimens for Friction Test}

Stainless steel SUS304 (JIS G4303) was used as a test material for the friction pair of ring and disk specimen. 


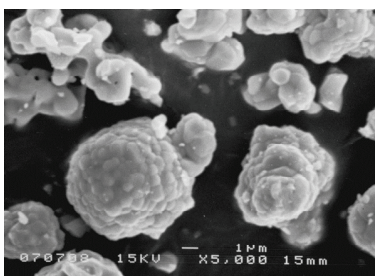

(a)

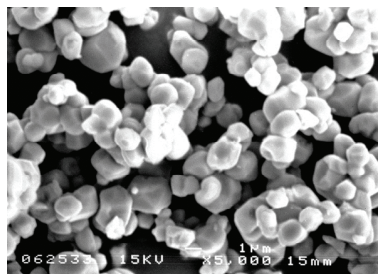

(c)

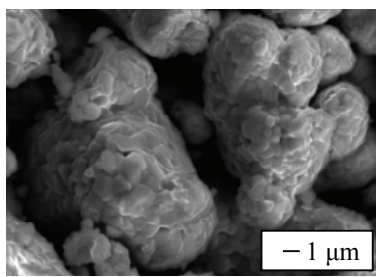

(b)

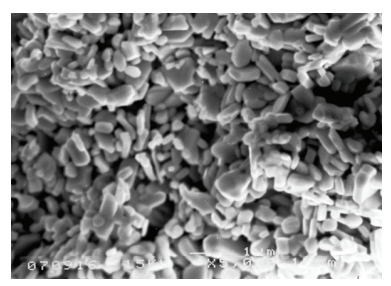

(d)
Fig. 4 Microscopic particle structures of (a) $\mathrm{Cu}_{3} \mathrm{Mo}_{2} \mathrm{O}_{9}$, (b) $\mathrm{CuMoO}_{4}$, (c) $\mathrm{CuO}$ and (d) $\mathrm{MoO}_{3}$ powders

The outer and inner diameter of the ring specimen were 20 and $15 \mathrm{~mm}$ respectively. The diameter and thickness of the disk specimen were 25 and $7 \mathrm{~mm}$ respectively. First of all, the sliding surface of ring specimen was slightly sandblasted with the alumina abrasives with the particle size less than $180 \mu \mathrm{m}$, and then washed in acetone by the ultrasonic cleaning process. The surface roughness of the blasted surface was controlled to be between 1.0 and $1.4 \mu \mathrm{m}(R a)$. Copper molybdates, $\mathrm{CuO}$ and $\mathrm{MoO}_{3}$ powders were accumulated on the blasted sliding surface as a powder coating. The quantity of accumulated powder on the sliding surface was estimated by measuring the weight of specimen before and after coating treatment, and it was controlled to be between 5 and $6 \mathrm{mg}$. The average thickness of the coating was estimated from the mass of accumulated coating, density of materials and coated area of specimen. The estimated thickness of $\mathrm{Cu}_{3} \mathrm{Mo}_{2} \mathrm{O}_{9}, \mathrm{CuMoO}_{4}, \mathrm{CuO}$ and $\mathrm{MoO}_{3}$ coating was about 8-10 $\mu \mathrm{m}, 11-13 \mu \mathrm{m}, 6-7 \mu \mathrm{m}$ and 8-9 $\mu \mathrm{m}$ respectively. The details of coating treatment and microscopic appearance configurations are described in our previous report [4].

\subsection{Friction Test}

The sliding test was conducted with the ring-on-disk apparatus with a furnace. The ring specimen was mounted to the rotating axis with the coated sliding surface up and the disk specimen was mounted to the linear axis. The disk specimen was pressed against the ring specimen from above. The applied pressure was $0.46 \mathrm{MPa}$ which correspond to the applied normal load of $61.8 \mathrm{~N}$. The sliding speed of the ring specimen was 55 $\mathrm{mm} / \mathrm{s}$ which correspond to the rotating speed of the ring specimen of $60 \mathrm{rpm}$. The sliding distance was $200 \mathrm{~m}$. The ambient temperature during sliding test was controlled to be from the room temperature to $700^{\circ} \mathrm{C}$ in this experiment. The temperature inside of the furnace was risen to the target temperature with the temperature increasing rate of $10^{\circ} \mathrm{C} / \mathrm{min}$. Friction test was conducted after maintaining the target temperature for $30 \mathrm{~min}$.

\section{Results}

\subsection{Friction Coefficient}

The variations of friction coefficient with time for each specimen tested at the ambient temperature of $700^{\circ} \mathrm{C}$ are shown in Fig. 5. Friction tests were conducted 3 times for each specimen and typical data are shown in this figure. Uncoated specimen showed high friction coefficient from 0.6 to 1.1 in the early half period of friction test and it showed relatively low friction coefficient around 0.5 in the later half period as shown in Fig. 5(a). $\mathrm{CuO}$ and $\mathrm{MoO}_{3}$ coated specimens showed variations of friction coefficient with time similar to that of uncoated specimen, however, they showed relatively low friction coefficient in comparison

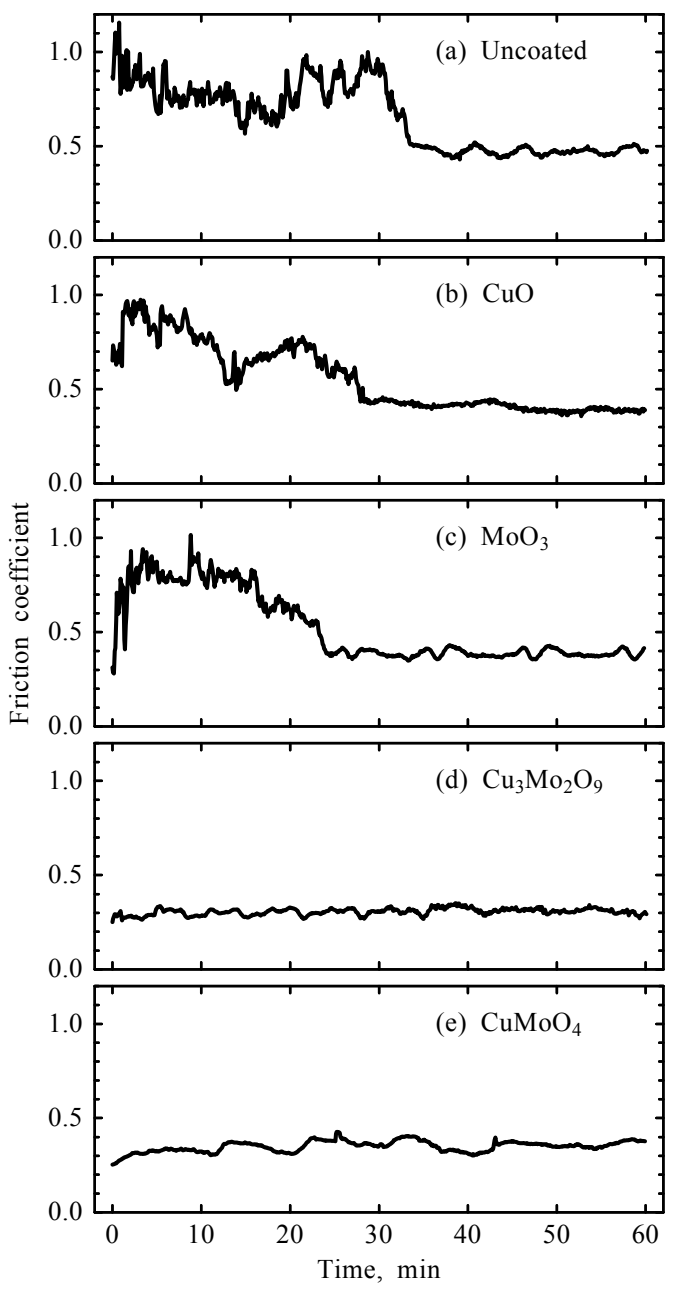

Fig. 5 Variations of friction coefficient with time tested at $700^{\circ} \mathrm{C}$ for (a) uncoated, (b) $\mathrm{CuO}$ coated, (c) $\mathrm{MoO}_{3}$ coated, (d) $\mathrm{Cu}_{3} \mathrm{Mo}_{2} \mathrm{O}_{9}$ coated and (e) $\mathrm{CuMoO}_{4}$ coated specimen 


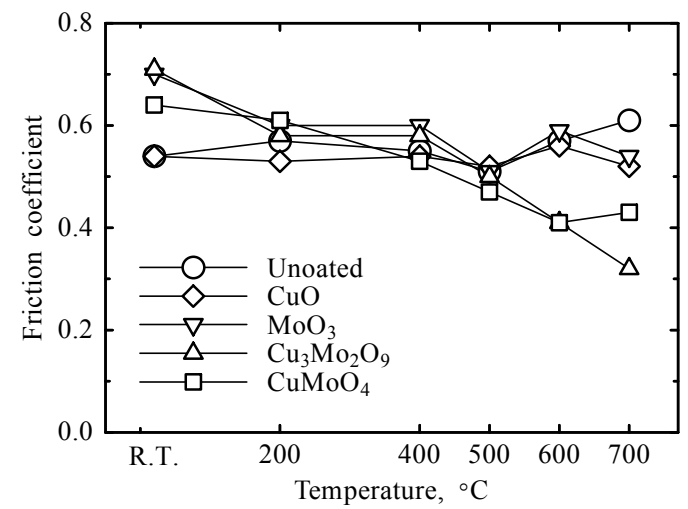

Fig. 6 Average friction coefficient of uncoated and four kinds of powder coated specimens for various ambient temperatures

with uncoated specimen as shown in Figs. 5(b) and 5(c). Both of copper molybdate coated specimens showed stable and low friction coefficient over entire period of friction test as shown in Figs. 5(d) and 5(e). $\mathrm{Cu}_{3} \mathrm{Mo}_{2} \mathrm{O}_{9}$ coated specimen showed remarkably stable and low friction coefficient around 0.3 .

Figure 6 shows the average friction coefficient, which was the friction coefficient averaged over entire period of friction test, of each specimen tested at various ambient temperatures from room temperature to $700^{\circ} \mathrm{C}$. The uncoated specimen showed little change in friction coefficient above 0.5 for the wide range of ambient temperature and showed high friction coefficient of over 0.6 at $700^{\circ} \mathrm{C}$. $\mathrm{CuO}$ and $\mathrm{MoO}_{3}$ didn't show the remarkable lubricity in this experiment. The friction coefficients of these specimens were above 0.5 for all ambient temperature conditions. Two kinds of copper molybdates showed high friction coefficient at room temperature, however, friction coefficients of these specimens decreased with increase of ambient temperature and showed good lubricity at the temperature above $500^{\circ} \mathrm{C}$. $\mathrm{Cu}_{3} \mathrm{Mo}_{2} \mathrm{O}_{9}$ coated specimen showed the lowest friction coefficient of 0.32 at $700^{\circ} \mathrm{C}$.

\subsection{Wear Amount of the Test Material}

Figure 7 shows the wear amount of ring specimen tested at various ambient temperatures. The wear amount of the specimen was obtained as a weight loss by measuring the weight of the specimen before and after the friction test. Preliminary to the friction test, it was confirmed that the weight increase of heated specimen by oxidation was negligibly small comparing with the wear amount. Although $\mathrm{MoO}_{3}$ and two kinds of copper molybdates showed high friction coefficient in comparison with uncoated and $\mathrm{CuO}$ coated specimens at room temperature as shown in Fig. 6, they showed small wear amount. As a general tendency, the wear amount of specimens increased with the increase of temperature, except, the wear amount of copper molybdate coated specimens at 600 and $700^{\circ} \mathrm{C}$. They showed very small

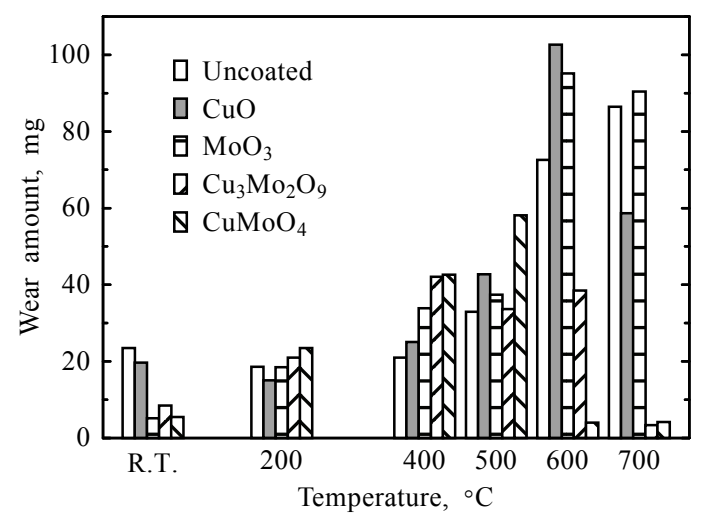

Fig. 7 Wear amount of uncoated and four kinds of powder coated ring specimens for various ambient temperatures

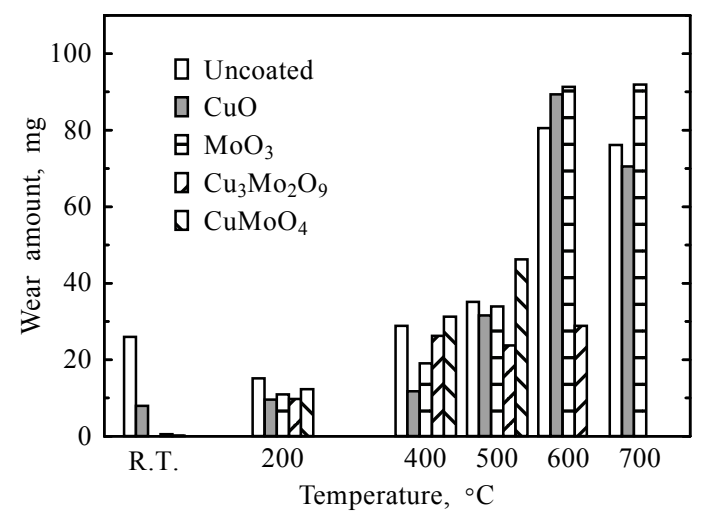

Fig. 8 Wear amount of disk specimens slid against uncoated and four kinds of powder coated ring specimens for various ambient temperatures

wear amount as expected from the low friction coefficient of these specimens at high temperature.

Figure 8 shows the wear amounts of disk specimens slid against ring specimen. It showed similar results as the results for the ring specimen. The wear amount of $\mathrm{CuMoO}_{4}$ coated specimen at $700^{\circ} \mathrm{C}$ and $\mathrm{Cu}_{3} \mathrm{Mo}_{2} \mathrm{O}_{9}$ coated specimen at 600 and $700^{\circ} \mathrm{C}$ were almost zero.

\subsection{Observation of the Friction Track}

Table 1 shows the sliding surface of uncoated, $\mathrm{MoO}_{3}$ coated and $\mathrm{Cu}_{3} \mathrm{Mo}_{2} \mathrm{O}_{9}$ coated ring specimens. The damage of the sliding surface of uncoated specimen became large with increase of the ambient temperature. The large amount of adhesion can be seen from the specimens tested at the high temperature above $400^{\circ} \mathrm{C}$. In the case of $\mathrm{MoO}_{3}$ coated specimen, it showed adhesive friction track tested at the temperature above $600^{\circ} \mathrm{C}$. $\mathrm{Cu}_{3} \mathrm{Mo}_{2} \mathrm{O}_{9}$ coated specimens showed damaged sliding surface at $400^{\circ} \mathrm{C}$, however, they showed smooth sliding surface when they slid at high temperature above $500^{\circ} \mathrm{C}$. 
Table 1 Sliding surface of uncoated, $\mathrm{MoO}_{3}$ coated and $\mathrm{Cu}_{3} \mathrm{Mo}_{2} \mathrm{O}_{9}$ coated ring specimens after friction test at various ambient temperatures

\begin{tabular}{|c|c|c|c|c|c|}
\hline $\begin{array}{c}\text { Ambient } \\
\text { temperature }\end{array}$ & R.T. & $400^{\circ} \mathrm{C}$ & $500^{\circ} \mathrm{C}$ & $600^{\circ} \mathrm{C}$ & $700^{\circ} \mathrm{C}$ \\
\hline Uncoated & & & & & \\
\hline $\begin{array}{l}\mathrm{MoO}_{3} \\
\text { coated }\end{array}$ & & & & & \\
\hline $\begin{array}{c}\mathrm{Cu}_{3} \mathrm{Mo}_{2} \mathrm{O}_{9} \\
\text { coated }\end{array}$ & & & & & \\
\hline
\end{tabular}

\section{Discussion}

The lubricity of many kinds of oxides especially at high temperature has been studied [1-5] and various kinds of high temperature lubricating mechanisms have been suggested [14-21]. Erdemir et al. introduced a crystal-chemical and quantum chemical approaches to understand the lubrication mechanisms of oxides at elevated temperatures $[14,15]$. They reported that oxides with high ionic potentials exhibit low shear strength and hence high lubricity. In the case of binary oxides, the lubricity increases as the difference in ionic potential increases especially at high temperature because the ability of oxides to form a low-melting-point or readily shearable compound improves with the increase of the difference in ionic potential, hence, they tends to show low hardness and low shear strength at elevated temperatures.

There are some kinds of molybdate besides copper molybdate. Lead molybdate is a potential solid lubricant for use at high temperature. Zabinski et al. investigated the lubricity of $\mathrm{PbMoO}_{4}$ film and they showed that stoichiometric and crystalline $\mathrm{PbMoO}_{4}$ film was lubricious as the temperature raised to $700^{\circ} \mathrm{C}$ [16]. They suggested that the decrease in friction coefficient is due to the decrease in shear strength of the material as the temperature approaches the melting point.

One of the other molybdates is silver molybdate. Gulbinski et al. studied the tribological properties of silver doped transition metal oxide coatings and concluded that $\mathrm{Ag}_{2} \mathrm{MoO}_{4}$ coating is the potential candidate for high temperature tribological applications $[17,18]$. They reported that the friction coefficient of $\mathrm{Ag}_{2} \mathrm{MoO}_{4}$ coating decreased with increasing temperature up to $500^{\circ} \mathrm{C}$ because of the gradual material softening. After the friction test at high temperature, $\mathrm{Ag}_{2} \mathrm{MoO}_{4}$ coating showed no change in XRD and Ramman spectra. This means that $\mathrm{Ag}_{2} \mathrm{MoO}_{4}$ coating is chemically stable under high temperature in their experiment. We have to note that this coating was deposited on the alumina substrate and rubbed with the alumina ball. Generally speaking, alumina is a chemically inert material at high temperature. On the other hand, the copper molybdate powder coating was formed on the stainless steel substrate in our experiment.

Aouadi et al. investigated the lubricity of three kinds of silver molybdate coatings, namely, $\mathrm{Ag}_{2} \mathrm{MoO}_{4}$, $\mathrm{Ag}_{2} \mathrm{Mo}_{2} \mathrm{O}_{7}$, and $\mathrm{Ag}_{2} \mathrm{Mo}_{4} \mathrm{O}_{13}$, at high temperature and they concluded that the superior lubricity of these silver molybdate coating is due to their layered structure with weaker Ag-O bridging bonds [19]. These relatively weak bonds may shear or break easily at high temperature.

Liu et al. studied the tribological properties of Ni-based composite with addition of $\mathrm{Ag}_{2} \mathrm{MoO}_{4}$ from room temperature to $700^{\circ} \mathrm{C}$, and it showed low friction coefficient and low wear rate at high temperature [20,21]. $\mathrm{Ag}_{2} \mathrm{MoO}_{4}$ decompose into $\mathrm{Ag}$ and $\mathrm{Mo}$ in their fabrication process of composite, however, $\mathrm{Ag}_{2} \mathrm{MoO}_{4}$ is reproduced in the rubbing process at high temperature. They mentioned that the layered structure with easily 
breakable bonds of silver molybdate is one of the reasons of low friction.

As described above, it seems that readily shearable nature due to softening or layered structure is recommended for the superior lubricity at high temperature conditions. Generally, oxides are hard and brittle material at room temperature. It was reported that oxides soften at the temperature above their ductile-to-brittle transition temperature [22], and it is typically about 40 to $70 \%$ of their melting point (in $\mathrm{K}$ ) [23]. The melting points of $\mathrm{CuO}, \mathrm{MoO}_{3}, \mathrm{Cu}_{3} \mathrm{Mo}_{2} \mathrm{O}_{9}$ and $\mathrm{CuMoO}_{4}$ are $1026,795,855$ and $820^{\circ} \mathrm{C}$ respectively. Hence, $\mathrm{CuO}$ could have ductile-to-brittle transition at the temperature between 250 and $640^{\circ} \mathrm{C}$. $\mathrm{CuO}$ powder could soften at the ambient temperature above $600^{\circ} \mathrm{C}$ if we take account the increase of temperature by frictional heat. The melting point of $\mathrm{CuO}$ is higher than that of copper molybdates, on the other hand, $\mathrm{MoO}_{3}$ and both of copper molybdates have no large difference in melting points and they could have ductile-to-brittle transition at less than $520^{\circ} \mathrm{C}$. Definitely, the changing of mechanical properties such as softening of these materials with increasing temperature must be one of the reasons for the lubricity at high temperature. However, we cannot explain the difference of the lubricity among $\mathrm{CuO}, \mathrm{MoO}_{3}$ and two kinds of copper molybdates at high temperature if softening of metal oxide is the only thing that could reduce friction and wear of specimen.

Metal oxides generally have little adhesiveness to metal surface, thus it is difficult to attach the oxide powders tightly to stainless steel specimen. In the friction test at room temperature, a considerable amount of powder lubricant could be swept away from the sliding surface because of their poor adhesiveness. However, copper molybdates showed superior lubricity and prevented a large amount of wear of ring and disk specimens at high temperature. Therefore, it was supposed that the enhanced adhesiveness of copper molybdate under high temperature condition could be one of the reasons of good tribological properties of these materials at high temperature.

Figure 9 shows the typical EPMA spectra obtained from the friction track of (a) $\mathrm{CuO}$, (b) $\mathrm{MoO}_{3},(\mathrm{c}) /(\mathrm{e})$ $\mathrm{Cu}_{3} \mathrm{Mo}_{2} \mathrm{O}_{9}$ and (d)/(f) $\mathrm{CuMoO}_{4}$ coated ring specimens tested at $700^{\circ} \mathrm{C}(\mathrm{a}, \mathrm{b}, \mathrm{c}, \mathrm{d})$ and $400^{\circ} \mathrm{C}(\mathrm{e}, \mathrm{f}) . \mathrm{CuO}$ or $\mathrm{MoO}_{3}$ powder coated specimen showed high friction coefficient and large wear amount of ring and disk specimens at $700^{\circ} \mathrm{C}$ as shown in Figs. 6-8. In the result of EPMA analysis of these specimens tested at $700^{\circ} \mathrm{C}$, $\mathrm{X}$-ray peaks of copper and molybdenum, which are constituent element of $\mathrm{CuO}$ or $\mathrm{MoO}_{3}$, were not detected from these friction track as shown in Figs. 9(a) and 9(b). In the case of $\mathrm{CuO}$ or $\mathrm{MoO}_{3}$ coated specimen, it was difficult to detect the signals of copper or molybdenum from the sliding surface tested not only at $700^{\circ} \mathrm{C}$ but also at other ambient temperatures. This means that $\mathrm{CuO}$ and $\mathrm{MoO}_{3}$ powder were easily removed from the sliding surface for wide range of ambient temperatures.

In the case of the specimens coated with two kinds of copper molybdates, they showed high friction coefficient and large wear amount of ring and disk specimens at $400^{\circ} \mathrm{C}$. As shown in Figs. 9(e) and 9(f), copper and molybdenum, which are constituent element of both copper molybdates, were not detected from the sliding surfaces of the specimens tested at $400^{\circ} \mathrm{C}$. On the other hand, they showed low friction coefficient and very small wear amount at $600^{\circ} \mathrm{C}$ and $700^{\circ} \mathrm{C}$, and the $\mathrm{X}$-ray peaks of copper and molybdenum were clearly detected as shown in Figs. 9(c) and 9(d). This means that adequate quantity of solid lubricant powder remained on the friction track till the end of friction test at $600^{\circ} \mathrm{C}$ and $700^{\circ} \mathrm{C}$. On the other hand, solid lubricant powder was easily removed from friction track at $400^{\circ} \mathrm{C}$.

Adhesiveness of lubricant to the substrate plays a significant role to maintain good lubricity. As the result of a series of friction test, the adhesiveness of metal

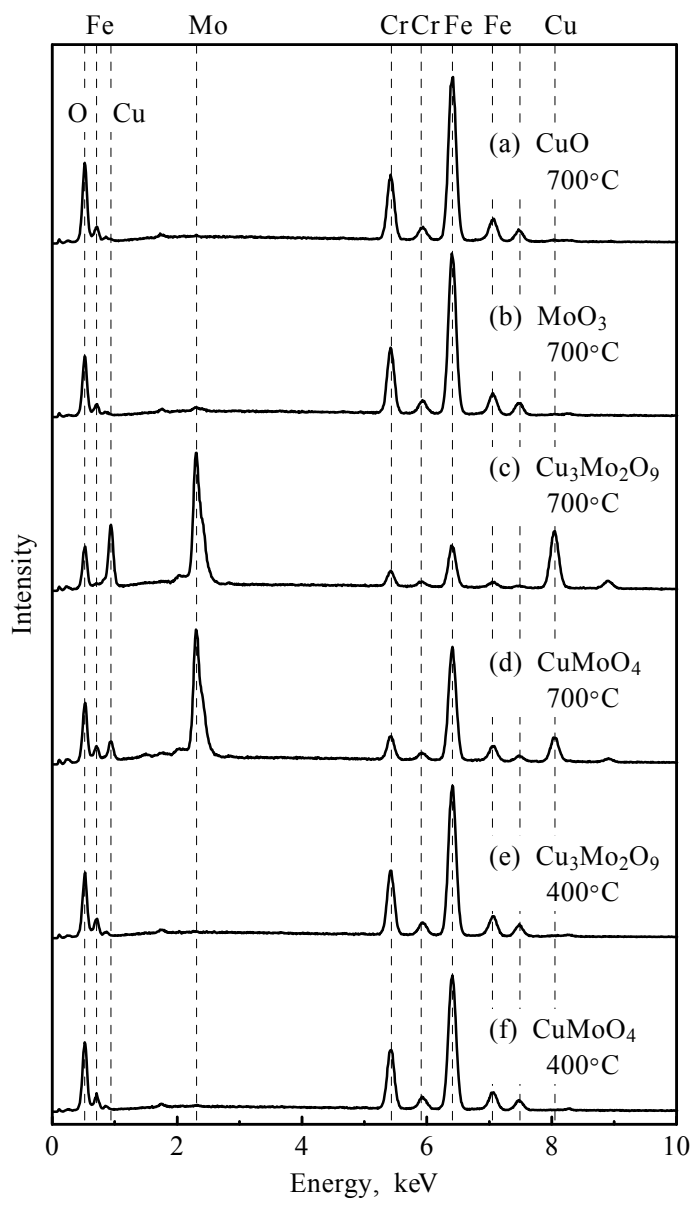

Fig. 9 Typical EPMA spectra obtained from friction track of (a) $\mathrm{CuO}$, (b) $\mathrm{MoO}_{3}$, (c) $\mathrm{Cu}_{3} \mathrm{Mo}_{2} \mathrm{O}_{9}$ and (d) $\mathrm{CuMoO}_{4}$ coated ring specimens tested at $700^{\circ} \mathrm{C}$ and (e) $\mathrm{Cu}_{3} \mathrm{Mo}_{2} \mathrm{O}_{9}$ and (f) $\mathrm{CuMoO}_{4}$ coated ring specimens tested at $400^{\circ} \mathrm{C}$ 


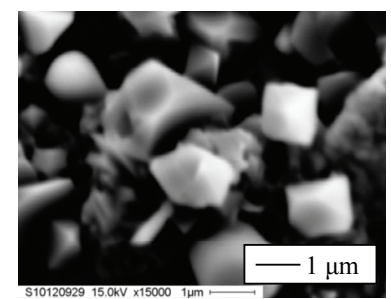

(a)

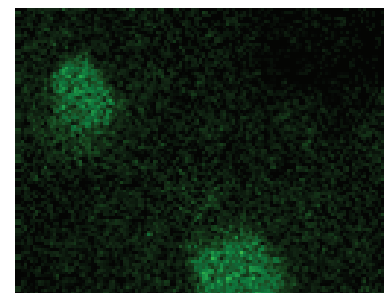

(c)

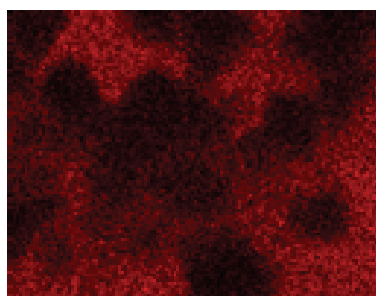

(b)

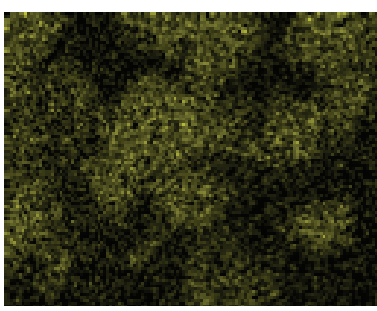

(d)
Fig. 10 (a) SEM image and X-ray images of (b) iron, (c) molybdenum and (d) copper obtained from $\mathrm{Cu}_{3} \mathrm{Mo}_{2} \mathrm{O}_{9}$ particles heated on the stainless steel substrate in air at $700^{\circ} \mathrm{C}$

oxides used in this friction test varies with the temperature and depends on the type of metal oxide. In order to investigate the adhesiveness of metal oxide powders to substrate, small quantity of $\mathrm{Cu}_{3} \mathrm{Mo}_{2} \mathrm{O}_{9}$ particles was heated on the stainless steel substrate in air at $700^{\circ} \mathrm{C}$ for 3 hours without friction. Figure 10 (a) show the SEM image of heated $\mathrm{Cu}_{3} \mathrm{Mo}_{2} \mathrm{O}_{9}$ particles and Figs. 10(b), 10(c) and 10(d) show the X-ray images of iron, molybdenum and copper respectively obtained from the same observation area of Fig. 10(a). The shape of particles changed from rounded shape (Fig. 4(a)) to more angulated shape by heating treatment. If most of the particles after heating treatment consist of copper molybdate, the X-ray of molybdenum and copper must be detected all together from the same position, however, they showed quite different distribution as shown in Figs. 10(c) and 10(d). This result suggests that copper molybdate reacts with the substrate and decomposes at high temperature. The particles were not pressed against substrate in this heating treatment. Therefore, the particles having direct contact with substrate could preferentially react with the substrate and consequently the reactive state on the substrate is different from place to place.

Though this reaction could be enhanced in the actual sliding surface because of applied load, newly generated material at sliding surface could be mixed with other materials during sliding and difficult to be observed by surface analysis method. So, in the next step, $\mathrm{CuO}$, $\mathrm{MoO}_{3}$ and two kinds of copper molybdates powder between the stainless steel substrates were heated at $700^{\circ} \mathrm{C}$ for 1 hour with a normal load and without sliding. Copper molybdate powder was spread uniformly on the substrate in the circular disk shape with the diameter of $13 \mathrm{~mm}$ and the applied normal load was $61.8 \mathrm{~N}$, thus the

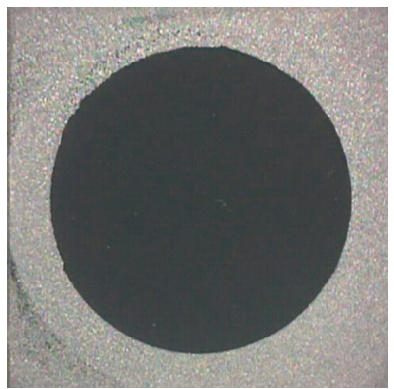

(a)

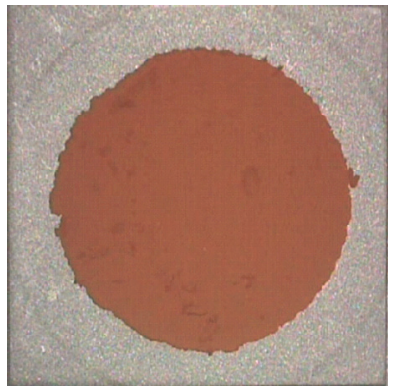

(e)

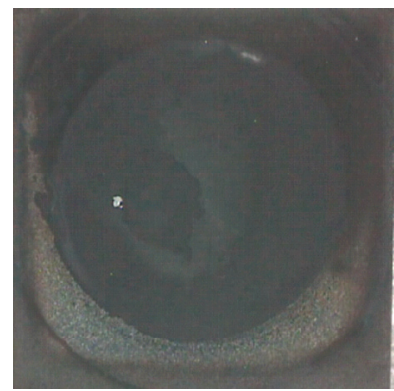

(b)

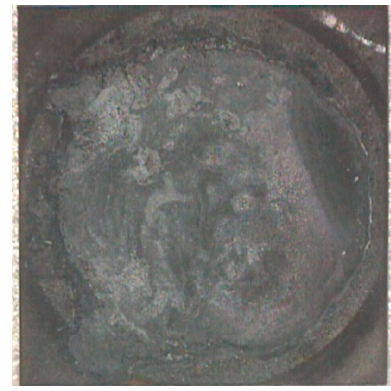

(f)

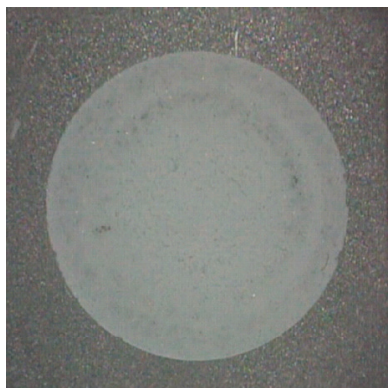

(c)

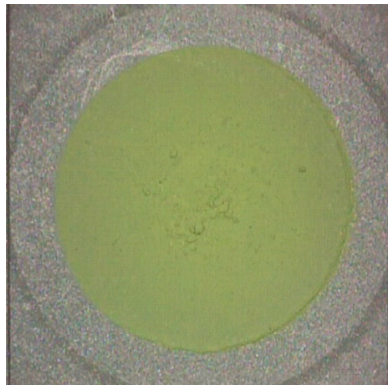

(g)

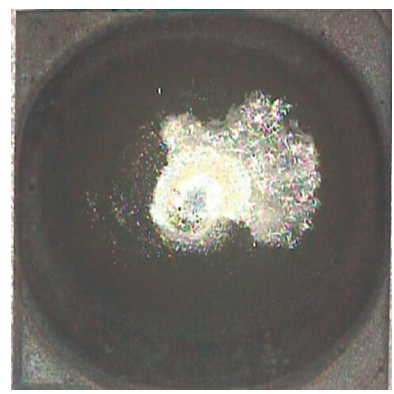

(d)

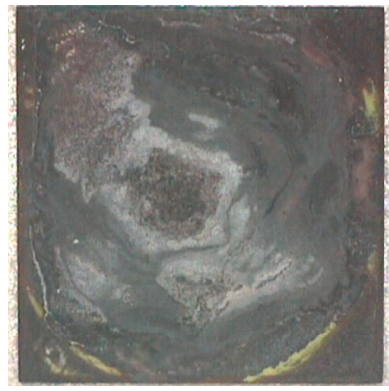

(h)

Fig. 11 (a)/(b) $\mathrm{CuO},(c) /(d) \mathrm{MoO}_{3},(e) /(f) \mathrm{Cu}_{3} \mathrm{Mo}_{2} \mathrm{O}_{9}$ and $(\mathrm{g}) /(\mathrm{h}) \mathrm{CuMoO}_{4}$ powders before $(\mathrm{a}, \mathrm{c}, \mathrm{e}, \mathrm{g})$ and after (b, d, f, h) heating treatment 
applied pressure in this treatment was about same as the applied pressure of friction test. The copper molybdate powder was pressed firmly against stainless steel substrates and then heated in this heating treatment. Therefore, a certain amount of copper molybdate could react with the substrate in comparison with the particles shown in Fig. 10.

Figure 11 shows the oxide powders before and after heating treatment. The brown $\mathrm{Cu}_{3} \mathrm{Mo}_{2} \mathrm{O}_{9}$ powder and yellowish $\mathrm{CuMoO}_{4}$ powder changed to the black ashy powder by heating treatment as shown in Figs. 11(e)/11(f) and $11(\mathrm{~g}) / 11(\mathrm{~h})$ respectively. The XRD spectra obtained from $\mathrm{CuO}$ and $\mathrm{MoO}_{3}$ powders and two kinds of copper molybdate powders before and after heating treatment are shown in Figs. 12 and 13 respectively. The diffraction peak patterns of CuO (JCPDS 01-080-1268), $\mathrm{MoO}_{3}$ (00-005-0508), $\mathrm{FeMoO}_{4}$ (01-089-2367), $\mathrm{Cu}_{3} \mathrm{Mo}_{2} \mathrm{O}_{9}, \mathrm{CuMoO}_{4}$ and $\mathrm{Cu}$ (00-004-0836) referred from the database are also shown in these figures. $\mathrm{CuO}$ powder showed no large difference in XRD spectrum before and after heating treatment as shown in Figs.

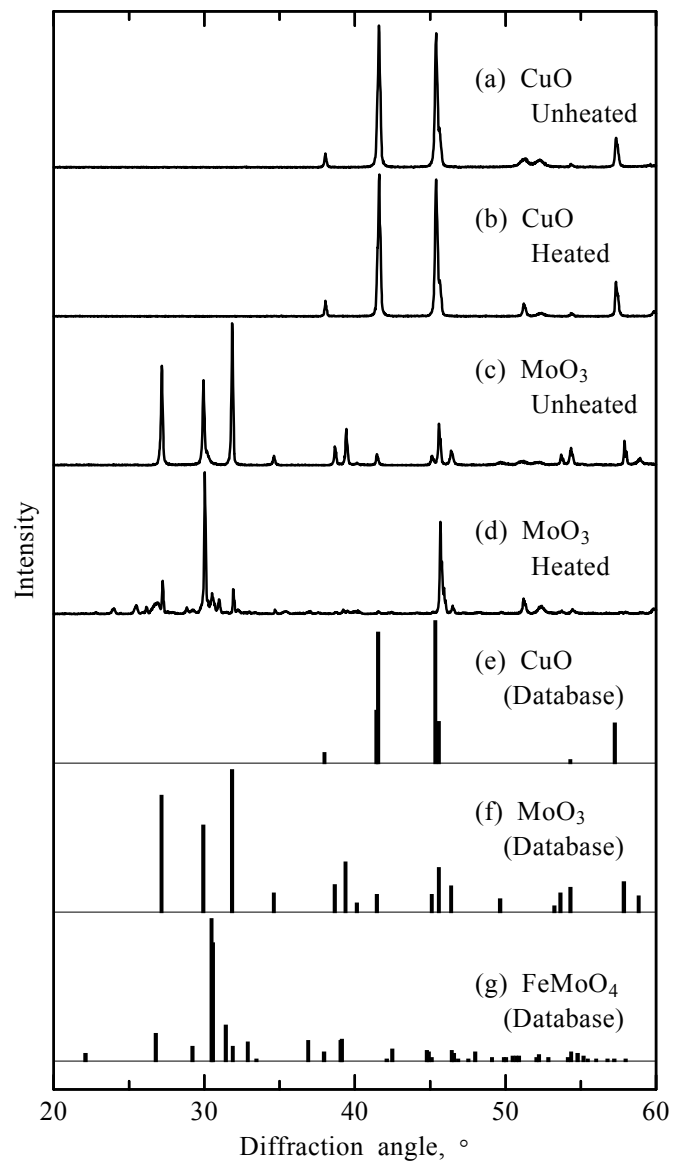

Fig. 12 XRD spectra obtained from (a)/(b) $\mathrm{CuO}$ and (c) $/(d) \mathrm{MoO}_{3}$ powders before (a, c) and after (b, d) heating treatment with diffraction peak patterns of (e) $\mathrm{CuO}$, (f) $\mathrm{MoO}_{3}$ and (g) $\mathrm{FeMoO}_{4}$ referred from the database 12(a) and 12(b). $\mathrm{MoO}_{3}$ powder showed remarkable change in spectrum as shown in Figs. 12(c) and 12(d). Small portion of $\mathrm{MoO}_{3}$ still remain after heating treatment and generation of $\mathrm{FeMoO}_{4}$ was confirmed from the spectra as shown in Fig. 12(d). The diffraction peaks obtained from $\mathrm{Cu}_{3} \mathrm{Mo}_{2} \mathrm{O}_{9}$ and $\mathrm{CuMoO}_{4}$ powder heated between the stainless steel substrates (Figs. 13(b) and 13(d)) are completely different from the diffraction peaks obtained from each powder before heating (Figs. 13(a) and 13(c)). As the result of diffraction peak matching, it was concluded that $\mathrm{FeMoO}_{4}$ and metal copper (unoxidized copper) were generated in both copper molybdates. On the other hand, unoxidized copper was not detected from $\mathrm{CuO}$ powder after heating as shown in Fig. 12(b).

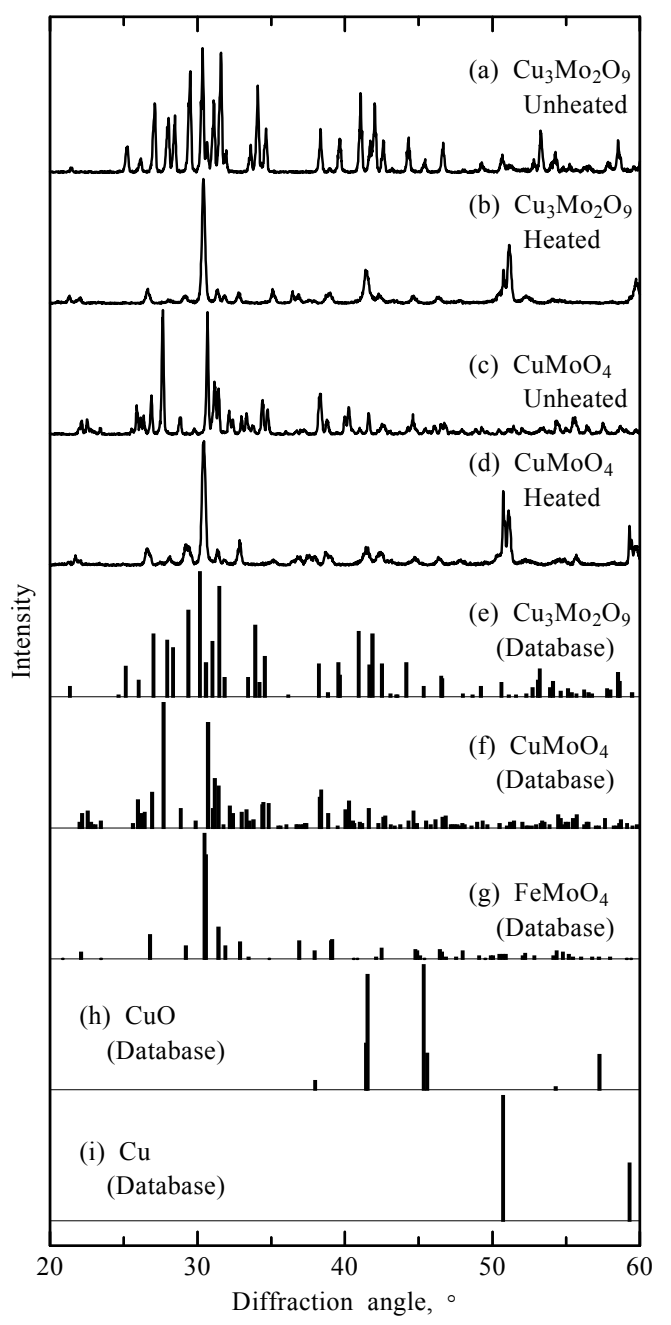

Fig. 13 XRD spectra obtained from (a)/(b) $\mathrm{Cu}_{3} \mathrm{Mo}_{2} \mathrm{O}_{9}$ and (c)/(d) $\mathrm{CuMoO}_{4}$ powders before $(\mathrm{a}, \mathrm{c})$ and after $(\mathrm{b}, \mathrm{d})$ heating treatment with diffraction peak patterns of (e) $\mathrm{Cu}_{3} \mathrm{Mo}_{2} \mathrm{O}_{9}$, (f) $\mathrm{CuMoO}_{4}$, (g) $\mathrm{FeMoO}_{4}$, (h) $\mathrm{CuO}$ and (i) $\mathrm{Cu}$ referred from the database 


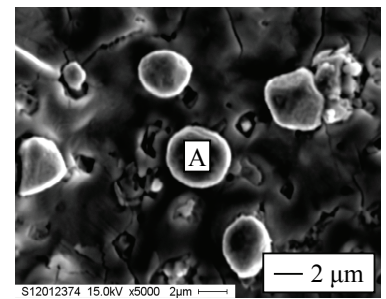

(a)

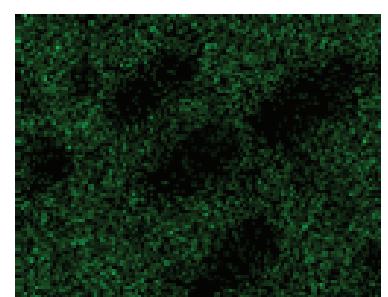

(c)

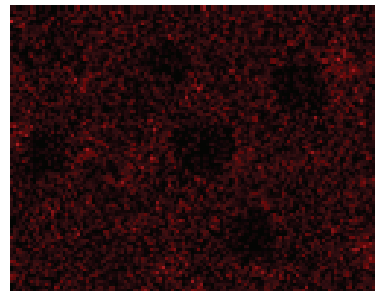

(b)

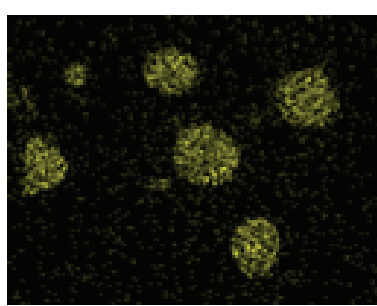

(d)
Fig. 14 (a) SEM image and X-ray images of (b) iron, (c) molybdenum and (d) copper obtained from $\mathrm{Cu}_{3} \mathrm{Mo}_{2} \mathrm{O}_{9}$ particles heated between the stainless steel substrate in air at $700^{\circ} \mathrm{C}$

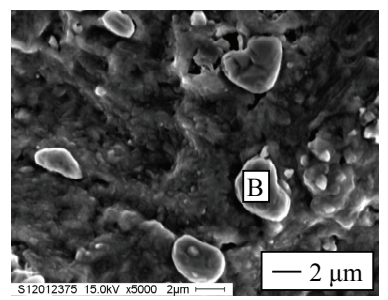

(a)

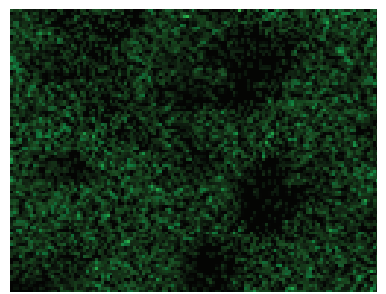

(c)

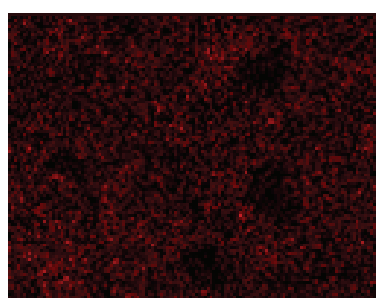

(b)

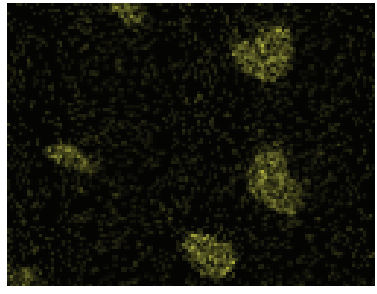

(d)
Fig. 15 (a) SEM image and X-ray images of (b) iron, (c) molybdenum and (d) copper obtained from $\mathrm{CuMoO}_{4}$ particles heated between the stainless steel substrate in air at $700^{\circ} \mathrm{C}$

In order to confirm the reaction of $\mathrm{Cu}_{3} \mathrm{Mo}_{2} \mathrm{O}_{9}$ and $\mathrm{CuMoO}_{4}$ powder heated between the stainless steel substrates, heated powders were analyzed by EPMA. Figures 14(a)/15(a) show the SEM image of heated $\mathrm{Cu}_{3} \mathrm{Mo}_{2} \mathrm{O}_{9}$ and $\mathrm{CuMoO}_{4}$ particles and Figs. 14(b)/15(b), $14(\mathrm{c}) / 15(\mathrm{c})$ and $14(\mathrm{~d}) / 15(\mathrm{~d})$ show the X-ray images of iron, molybdenum and copper, respectively. Molybdenum and copper showed quite different distribution as shown in Figs. 14(c)/15(c) and 14(d)/15(d). Figure 16 show the EPMA spectra obtained

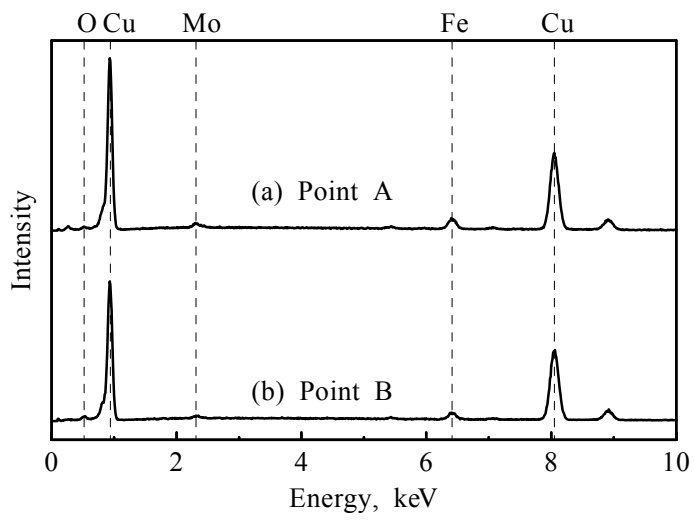

Fig. 16 EPMA spectra obtained from (a) point $\mathrm{A}$ in Fig. 14 and (b) point B in Fig. 15

from point A and B in the Figs. 14(a) and 14(a). The strong peak of copper was detected and peak of oxygen was negligibly small at each point. If the spectra were obtained from $\mathrm{CuO}$, a large oxygen peak should be detected. From the result of XRD analysis and EPMA analysis, there is almost no doubt that unoxidized copper was generated by heating copper molybdate contacting with stainless steel.

The generation of unoxidized copper could be the result of oxidoreduction reaction of copper molybdate. Figure 17 shows XRD spectra obtained from $\mathrm{Cu}_{3} \mathrm{Mo}_{2} \mathrm{O}_{9}$ powders before and after heating treatment. $\mathrm{Cu}_{3} \mathrm{Mo}_{2} \mathrm{O}_{9}$ powder was heated between alumina $\left(\mathrm{Al}_{2} \mathrm{O}_{3}\right)$ substrates in this heating treatment and the treatment conditions are same with previous heating treatment. Although $\mathrm{Cu}_{3} \mathrm{Mo}_{2} \mathrm{O}_{9}$ powder showed large difference in XRD spectrum before and after heating treatment in the case of stainless steel substrates as shown in Figs. 13(a) and 13(b), it showed no large difference in XRD spectrum in the case of alumina substrates as shown in Figs. 17(a) and 17 (b). Hence, it can be concluded that iron content is required for the oxidoreduction reaction of copper

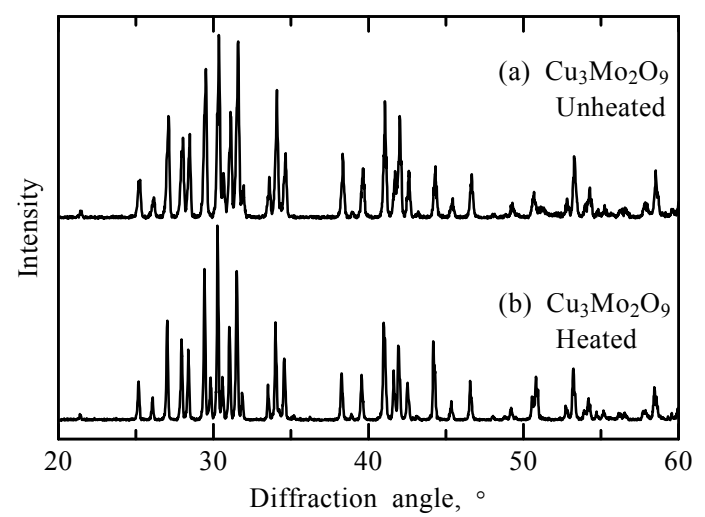

Fig. 17 XRD spectra obtained from $\mathrm{Cu}_{3} \mathrm{Mo}_{2} \mathrm{O}_{9}$ powders (a) before and (b) after heating treatment between alumina substrates 
molybdate.

Although it is not known exactly why the unoxidized copper was escaped from oxidation in the high temperature atmosphere while it is cooled down to the room temperature, lack of oxygen due to the configuration of specimen might be the reason of this phenomena. The amount of oxygen in the ambient air which reacts with the powder should be limited because the small quantity of copper molybdenum powder is pressed thinly and tightly between the stainless steel substrates during heating treatment.

The generation of $\mathrm{FeMoO}_{4}$ suggests that copper molybdate reacts with iron, which is the major constituent of stainless steel. The adhesiveness of lubricant could be increased by the reaction between solid lubricant and substrate, and then a certain amount of the solid lubricant could be maintained on the sliding surface under high temperature conditions. On the other hand, the unoxidized copper could work as soft metal lubricant at high temperature and reduce friction. It was suggested that softening of copper molybdate at high temperature [5] reduced friction coefficient and reduced wear amount of specimens. Beyond that, it was supposed that the reaction between copper molybdate and substrate maintaines sufficient amounts of solid lubricant on the sliding interfaces, and that the generation of unoxidized copper enhances lubricating properties of solid lubricant.

\section{Conclusions}

The lubricity of two kinds of copper molybdate powders $\mathrm{Cu}_{3} \mathrm{Mo}_{2} \mathrm{O}_{9}$ and $\mathrm{CuMoO}_{4}$ and two kinds of single metal oxide powders $\mathrm{CuO}$ and $\mathrm{MoO}_{3}$ supplied to the sliding surface of stainless steel substrate were studied under the temperatures from room temperature to $700^{\circ} \mathrm{C}$. Both of copper molybdate powders showed low friction coefficient with increasing temperature. On the other hand, $\mathrm{CuO}$ and $\mathrm{MoO}_{3}$ powders showed poor lubricating ability and they showed large wear amount of specimens comparing with two kinds of copper molybdate. It was revealed that copper molybdates react with the stainless steel substrate at high temperature and generate $\mathrm{FeMoO}_{4}$ and unoxidized copper. The reaction of copper molybdate with substrate results in a good adhesiveness of solid lubricant to substrate and it enhances maintaining ability of the lubricant on the friction track. This reaction generates unoxidized copper and it could assist reducing friction as a soft metal lubricant. It was suggested that the generation of soft metal could enhance a lubricity of solid lubricant in addition to a well-known lubricating mechanism of metal oxide at high temperature.

\section{Acknowlegement}

This work was supported by JSPS Grant-in-Aid for Young Scientists (B): 21760112 and Grant-in-Aid for Scientific Research (C): 25420089.

\section{References}

[1] Peterson, M. B., Murray, S. F. and Florek, J. J., "Consideration of Lubricants for Temperatures above 1000 F," ASLE Transactions, 2, 2, 1959, 225-234.

[2] Peterson, M. B., Florek, J. J. and Lee, R. E., "Sliding Characteristics of Metals at High Temperatures," ASLE Transactions, 3, 1, 1960, 101-109.

[3] Peterson, M. B., Calabrese, S. J., Li, S. and Jiang, X., "Friction of Alloys at High Temperature," Journal of Materials Science and Technology, 10, 5, 1994, 313-320.

[4] Takeichi, Y., Chujyo, T., Okamoto, N. and Uemura, M., "Effects of Molybdenum Trioxide on the Tribological Properties of Aluminum Bronze under High Temperature Conditions," Tribology Online, 4, 5, 2009, 135-139.

[5] Wahl, K. J., Seitzman, L. E., Bolster, R. N., Singer, I. L. and Peterson, M. B., "Ion-Beam Deposited $\mathrm{Cu}-\mathrm{Mo}$ Coatings as High Temperature Solid Lubricants," Surface and Coatings Technology, 89, 3, 1997, 245-251.

[6] Haber, J., Stoch, J. and Wiltowski, T., "Surface Transformations of Copper Oxidation Catalysts," Reaction Kinetics and Catalysis Letters, 13, 2, 1980, 161-165.

[7] Hasan, M. A., Zaki, M. I., Kumari, K. and Pasupulety, L., "Soot Deep Oxidation Catalyzed by Molybdena and Molybdates a Thermogravimetric Investigation," Thermochimica Acta, 320, 1-2, 1998, 23-32.

[8] Ghorai, T. K., Dhak, D., Dalai, S. and Pramanik, P., "Effect of Photocatalytic Activities of Nano-Sized Copper Molybdate $\left(\mathrm{CuMoO}_{4}\right)$-Doped Bismuth Titanate $\left(\mathrm{Bi}_{2} \mathrm{Ti}_{4} \mathrm{O}_{11}\right)$ (CMBT) Alloy," Materials Research Bulletin, 43, 7, 2008, 1770-1780.

[9] Nassau, K. and Abrahamis, S. C., "The Growth and Properties of Single Crystal Cupric Molybdate," Jounal of Crystal Growth, 2, 3, 1968, 136-140.

[10] Machej, T. and Ziolkowski, J., "Phase Diagram of the $\mathrm{CuO}-\mathrm{MoO}_{3}$ System," Materials Chemistry, 4, 1979, 113-121.

[11] Machej, T. and Ziolkowski, J., "Subsolidus Phase Diagram of $\mathrm{Cu}_{2} \mathrm{O}-\mathrm{CuO}-\mathrm{MoO}_{3}$ System," Journal of Solid State Chemistry, 31, 2, 1980, 135-143.

[12] Steiner, U., Reichelt, W. and Oppermann, H., "Coexistence Relations, Preparation and Properties of Ternary Compounds in the System $\mathrm{Cu} / \mathrm{Mo} / \mathrm{O}$," Journal of Inorganic and General Chemistry, 622, 1996, 1428-1434 (in German).

[13] Sun, A., Wang, D., Wu, Z. and Zan, X., "Synthesis of Ultra-Fine Mo-Cu Nanocomposites by Coreduction of Mechanical-Activated $\mathrm{CuMoO}_{4}-\mathrm{MoO}_{3}$ Mixtures at Low Temperature," Journal of Alloys and Compounds, 505, 2-3, 2010, 588-591. 
[14] Erdemir, A., "A Crystal-Chemical Approach to Lubrication by Solid Oxides," Tribology Letters, 8, 2-3, 2000, 97-102.

[15] Erdemir, A., Li, S. and Jin, Y., "Relation of Certain Quantum Chemical Parameters to Lubrication Behavior of Solid Oxides," International Journal of Molecular Sciences, 6, 6, 2005, 203-218.

[16] Zabinsiki, J. S., Day, A. E., Donley, M. S., Dellacorte, C. and McDevitt, N. T., "Synthesis and Characterization of a High-Temperature Oxide Lubricant," Journal of Materials Science, 29, 22, 1994, 5875-5879.

[17] Gulbinski, W., Suszko, T., Sienicki, W. and Warcholinski, B., "Tribological Properties of Silver- and Copper-Doped Transition Metal Oxide Coatings," Wear, 254, 1-2, 2003, 129-135.

[18] Gulbinski, W. and Suszko, T., "Thin Films of $\mathrm{MoO}_{3}-\mathrm{Ag}_{2} \mathrm{O}$ Binary Oxides - The High Temperature Lubricants," Wear, 261, 7-8, 2006, 867-873.

[19] Aouadi, S. M., Paudel, Y., Simonson, W. J., Ge, Q., Kohli, P., Muratore, C. and Voevodin, A. A., "Tribological Investigation of Adaptive
$\mathrm{Mo}_{2} \mathrm{~N} / \mathrm{MoS}_{2} / \mathrm{Ag}$ Coatings with High Sulfur Content," Surface \& Coatings Technology, 203, 10-11, 2009, 1304-1309.

[20] Liu, E. Y., Wang, W. Z., Gao, Y. M. and Jia, J. H., "Tribological Properties of Adaptive Ni-Based Composites with Addition of Lubricious $\mathrm{Ag}_{2} \mathrm{MoO}_{4}$ at Elevated Temperatures," Tribology Letters, 47, 1, 2012, 21-30.

[21] Liu, E. Y., Gao, Y. M., Wang, W. Z., Zhang, X. L., Wang, X., Yi, G. W. and Jia, J. H., "Effect of $\mathrm{Ag}_{2} \mathrm{Mo}_{2} \mathrm{O}_{7}$ Incorporation on the Tribological Characteristics of Adaptive Ni-Based Composite at Elevated Temperatures," Tribology Transactions, 56, 3, 2013, 469-479.

[22] Sliney, H. E., Jacobson, T. P., Deadmore, D. and Miyoshi, K., "Tribology of Selected Ceramics at Temperatures to $900 \mathrm{C}$," Ceramic Engineering and Science Proceedings, 7, 7/8, 2008, 1039-1051.

[23] Atkins, A. G. and Tabor, D., "Hardness and Deformation Properties of Solids at Very High Temperatures," Proceedings of the Royal Society of London, Ser.A, 292, 1431, 1966, 441-459. 